\title{
Report on the rehabilitation of the roof structure over the tennis stadium at Hamburg Rothenbaum
}

\author{
Alfred Rein* \\ *Alfred Rein Ingenieure $\mathrm{GmbH}$ \\ Fuchseckstraße 7, 70188 Stuttgart, Germany \\ e-mail: mail@ar-ingenieure.com,web page: www.ar-ingenieure.com
}

\begin{abstract}
The stadium roof over the tennis stadium at Hamburg's Rothenbaum, completed in 1998 based on a design by the architectural office Schweger + Partner and the engineering office Sobek und Rieger, was considered one of the most modern and innovative stadium roofs at the time of its opening. It has a fixed outer roof and a convertible inner roof, which with $3000 \mathrm{~m}^{2}$ was the largest convertible roof in Europe at that time. In addition to the convincing overall design, the special feature lies in particular in the drive technology of the convertible inner roof, in which winches for moving and hydraulic cylinders for tensioning were used for the first time. This technology proved its reliability, so that subsequently most large stadium roofs were equipped with this type of driving mechanism. In this respect, the stadium roof at the Rothenbaum in Hamburg can be regarded as a prototype for subsequent generations of retractable stadium roofs.
\end{abstract}

After 20 years of use and an increasingly obvious need for reconditioning, the German Tennis Association (DTB) decided in 2018 to repair the roof structure. This was made possible by a generous donation from the Hamburg-based company ECE Projektmanagement, which not only financed the necessary repair work on the roof structure, but also enabled a general overhaul of the entire stadium complex into a modern sports facility that meets the requirements of the times.

After an analysis of the required repairs, Alfred Rein Ingenieure was commissioned at the end of 2018 with the overall planning of the work on the roof structure. Alfred Rein had already been involved in the planning of the new building from 1995 to 1998 in the office of Sobek and Rieger as projectleading engineer and was familiar with the conditions.

The scope of the repair work included an inspection and testing of the cable structure, refit of the corrosion protection of the steel structure, replacement of the membranes of the inner and outer roofs and complete overhaul of the drives.

The work was carried out under a tight schedule, as the Beach Volleyball World Championships were to be held under a renovated, fully operating inner roof in early summer of 2019. The replacement of the membranes of the outer roof with the other remaining work, which also included a state-of-the-art safety technology, took place up to November 2020.

In the presentation, the condition of the roof structure before renovation and the applied methods and measures of repair will be reported. Conclusions and optimizations for future projects can be drawn from the analysis of age-related wear. 